\title{
XERODERMA PIGMENTOSA WITH MULTIPLE CUTANEOUS MALIGNANCIES - A RARE CASE REPORT AND REVIEW OF LITERATURE
}

\author{
Rohan Shetty ${ }^{1}$, Girish B.S. ${ }^{2}$, Rajesh Ballal ${ }^{3}$, Harish S. Permi ${ }^{4}$, \\ Pramodh Makannavar ${ }^{5}$ \& Vinay Alva ${ }^{6}$. \\ ${ }^{1}$ Assistant Professor, Department of Surgery, ${ }^{2}$ Associate Professor, Department of Dermatology. \\ ${ }^{3}$ Professor, Department of Surgery, ${ }^{4}$ Associate Professor, Department of Pathology. \\ ${ }^{5}$ Post graduate, Department of Surgery, ${ }^{6}$ Post graduate, Department of Surgery. \\ K.S. Hedge Medical Academy, Nitte University, Deralakatte, Mangalore - 575018 ,

\section{Correspondence:} \\ Rohan Shetty \\ Assistant Professor, Department of Surgery, K.S. Hedge Medical Academy, Nitte University, Deralakatte, Mangalore - 575018 , \\ E-mail : shettyrohan@rediffmail.com \\ Xeroderma pigmentosa is a rare autosomal recessive disorder, characterized by photosensitivity, pigmentary changes, premature skin \\ aging, and marked increase in risk of developing malignant neoplasms of the skin and eyes. Here we present a 13 year old girl with \\ xeroderma pigmentosa who developed multiple cutaneous malignancies in the face and upper limb.
}

Abstract :

Keywords : Xeroderma pigmentosa, multiple skin cancer, squamous cell carcinoma, basal cell carcinoma

\section{Introduction:}

Xerodermatosa pigmentosa is a heriditary autosomal recessive disorder, characterized by mucocutaneous and ocular hypersensitivity to UV radiation. The prevalence of $\mathrm{XP}$ in United states \& Europe is 1:1,000.000 and in Japan 1:100,000, its incidence is not significant in India (1). The basic defect underlying this condition is nucleotide excision repair defect (NER) leading to defective repair of DNA damaged by UV radiation. (2)

\section{Case Report :}

A 13 year old girl with Xeroderma pigmentosa who was under the treatment in department of dermatology for the same was referred to surgery for the large ulcer over her right forearm (figure 1) and two ulcerated nodules over the

\begin{tabular}{|c|}
\hline Access this article online \\
\hline Quick Response Code \\
\hline
\end{tabular}
face(figure 2). There were no axillary or cervical I y m h $\quad \mathrm{node}$ enlargements. She underwent wide excision and skin grafting for forearm lesion (figure 3) and excision and primary closure for facial lesions (figure 4). Histopathology showed the lesion excised from the forearm was squamous cell carcinoma and between the two lesions excised from the face, one found to have basal cell and another squamous cell carcinoma. Patient was normal for 3 months, and then developed a small nodule over the excised area of the right forearm. She was advised re excision, however family refused further treatment. The younger brother of the patient 9 years old was also suffering from xeroderma pigmentosa but without any cutaneous malignant changes. There was no family history or history of consanguineous marriage.

\section{Discussion :}

Xeroderma pigmentosum is a rare autosomal recessive disorder, first described in 1874 by Hebra and Kaposi.In 1812, Kaposi coined the term Xeroderma pigmentosum. In these patients excessive solar damage to the skin develops at an early stage. Three stages are recognized. First usually starts at when the child is 1-2 years old, there occurs slight diffuse erythema associated with scaling and small areas of hyperpigmentation, resembling freckle. In the second stage, atrophy of the skin, mottled pigmentation, and 
telengectasia develops which gives to the skin an appearance similar to that of chronic radio dermatitis. Third stage usually starts in adolescence; various types of malignant tumors of the skin appear. (3)

About $50 \%$ of persons with xeroderma pigmentosum experience acute sun burn on minimal exposure to UV radiation and tend to develop neurological abnormalities. Cutaneous signs and symptoms usually emerge in children under the age of 20 years. Up to $60 \%$ of persons with xeroderma pigmentosum will eventually develop skin cancer, in many cases multiple primary lesions. (4)

The mean age at diagnosis of Xeroderma pigmentosum associated skin cancer is 8 years, 50 years younger than in general population. Xeroderma pigmentosum patients below 2years of age have more than 1000 fold increased risk of developing skin cancer. The two most common types of cancer found in Xeroderma patients are BCC and SCC, mainly occurring in head face and neck. Melanomas occur in one fourth of cases. A patient presenting with any two of these malignancies is a rare occurrence, with only few reported in literature. The presence of all three types is extremely rare.(5)

Ocular manifestations include photophobia as the earliest symptom, which is a feature of keratitis. This was seen in our case .Other ocular complications include exposure keratitis, vascularisation, ulceration, nodular dystrophy, and uveitis. Neurologic defects are detected in $20-30 \%$ of patients with Xeroderma pigmentosum. Microcephaly, delayed motor development, sensory neural deafnes are commonly seen. However in our case, these were not there.(6)

Currently there is no specific treatment for Xeroderma pigmentosum. Management involves preventing damage and dealing with damage tissue at the earliest. Total protection from UV light greatly improves the prognosis and reduces skin changes and cancers. This is achieved by protective clothing(long opaque clothes, sun hats, UV protective sun glasses with side shields, long hair styles, custom made face shields), protective film on window, restricting outdoor activities to night time and frequent application of high factor sunscreen even indoors.(7)

Surveillance is another important aspect. Dermatologists review once in 3 months ophthalmology examination annually, regular neurological review and hearing tests are worthwhile. Vitamin D supplements may be needed, since sunlight is excluded. Premalignant lesions are treated with topical 5-FU or cryotherapy. Malignant lesions should be identified early and excised surgically. (8)

The progression varies with severity of the genetic disorder, the success in avoiding UV light and vigilance of screening. It also depends on its extent of neurological involvement. Previously the prognosis was a reduced life expectancy due to advanced skin cancers or neurological complications. However recent information suggests that a normal life span is possible for patients without neurological problems, who are fully protected from UV light(9). Prenatal diagnosis is the only way to prevent this disease. This is done by amniocentesis and invitro cell culture and detection of defective DNA repair.(10)

In our case, patient sought medical advice very late, during which damage had already occurred. Also because of the sunny climate and lack of sun protection at home, she suffered continued skin damage. However there were no neurological abnormalities.

\section{Conclusion :}

Xeroderma pigmentosa is an extremely rare condition in India. Our case was unique one, as there was no family history or consaginous marriage. Both children of the family were affected. This case was presented to create awareness among treating physicians and surgeons about this rare condition and importance of early detection and prevention of UV rays induced skin damage. 


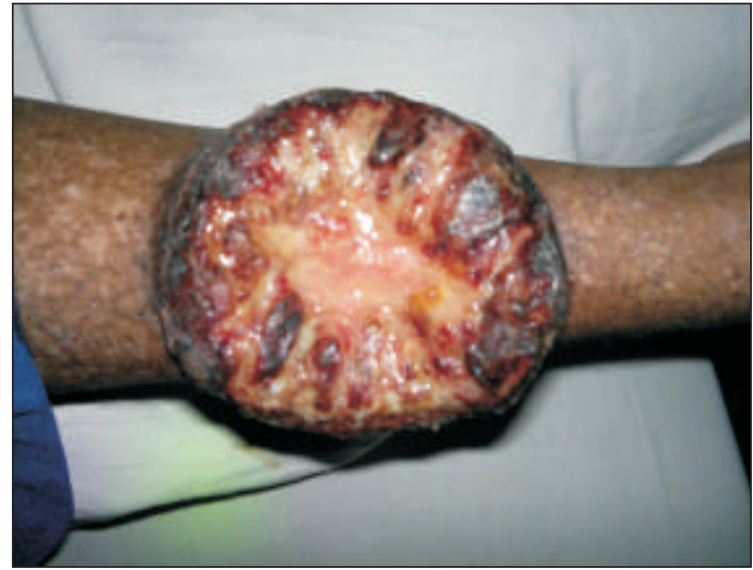

Figure 1. : Squamous cell carcinoma over the right forearm

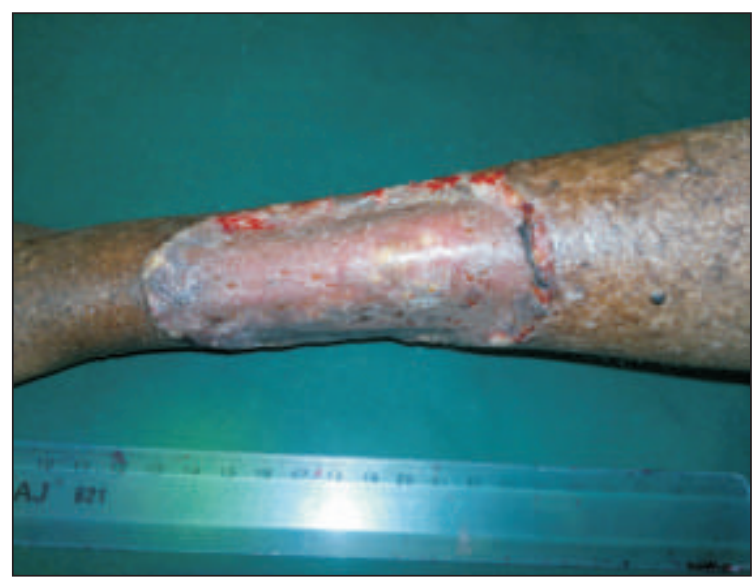

Figure 3. : Post excision and skin grafting

References:

1. Mohanty P. Mohanty I, Devi BP, Multiple cutaneous malignancies in xerodema pigmentosum, Indian J Dermatol Venereol Leprol 2001; 67; 96-97.

2. Pradhan E, Padhye SB, Malla OK, Karki KJD, Case of xeroderma pigmentosum with well differentiated squamous cell carcinoma in the eye, Kathmandu Univ Med 2003; 4; 278-83

3. Marwah N, Garg S, Chhabra S, Dayal S, Sen R, Malignant melanoma in a case of xeroderma pigmentosum, Egyptian dermatology Online Journal 2011; Vol. 7 No 2:11

4. L. Feller, N.H Wood, M.H Motswaledi, R.A.G. Khammissa, M.Meyer, J. Lemmer, Xeroderma pigmentosum: a case report and review of literature, J PREV MED HYG 2010: 51; 87-91

5. Vandana U Grampurohit, U.S Dinesh, Ravikala Rao, Multiple cutaneous malignancies in a patient of xeroderma pigmentosum, Journal of Cancer Research and Therapeutics 2011; Vol 7 Issue 2 ; 205- 207

6. S. Pathy, K.K Naik, Suman Bhasker, M. C Sharma, P.K. Julka, G.K. Rath, Squamous cell carcinoma of face with Xeroderma Pigmentosa - A case report, Indian Journal of Medical \& Pediatric oncology 2005; Vol 26 No. 1, 47- 49.

7. Runger TM, DiGiovanna JJ, Kraemer KH, Hereditary disorders of genome instability and DNA repair. In;Wolff K, Goldsmith LA, Katz SI, et al. Fitzpatrick's dermatology in general medicine. $7^{\text {th }}$ edition. New York: McGraw Hill Co 2008, pp.1311-25

8. Kraemer KH, Lee M, Scotto J, Xeroderma pigmentosum - cutaneous, ocular, and neurological abnormalities in 830 published cases. Arch Dermatol 1987; 123:241-80

9. Webb S; Xeroderma Pigmentosum, BMJ, 2008 Feb 23 ${ }^{\text {rd }}$, 336(7641): 444-6

10. Ramsay CA, CultartTM, Blunt S, Pawsey SA and Giaqneneli F. Prenatal diagnosis of Xeroderma pigmentosum: Report of first successful case. Lancet 1974; 2:1109-1112

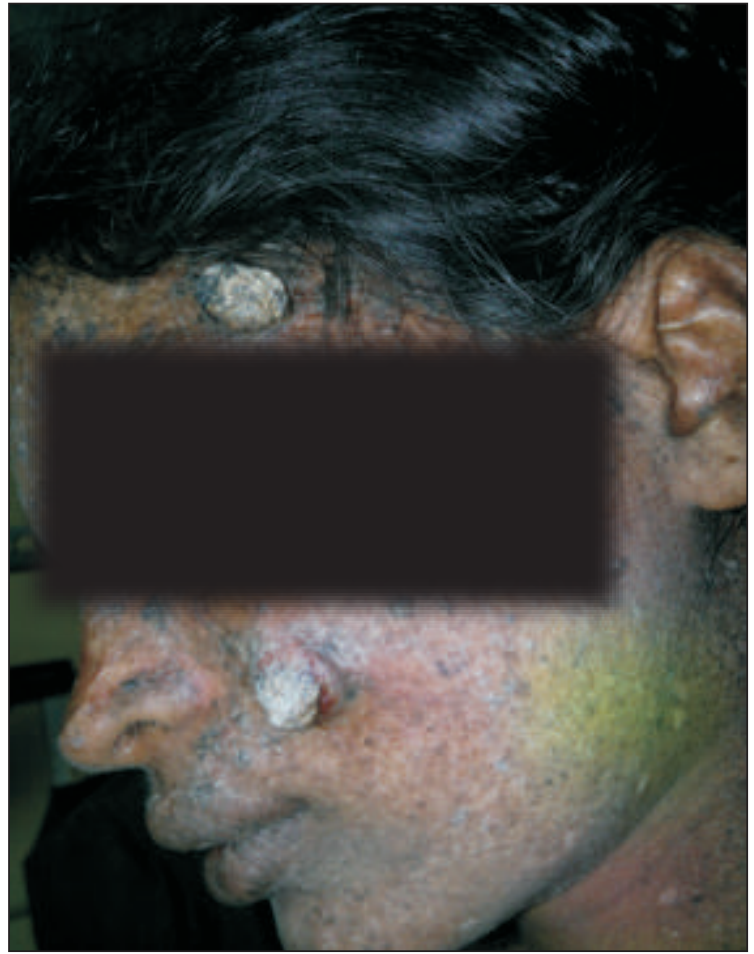

Figure 2. : Squamous and Basal cell carcinoma over the face

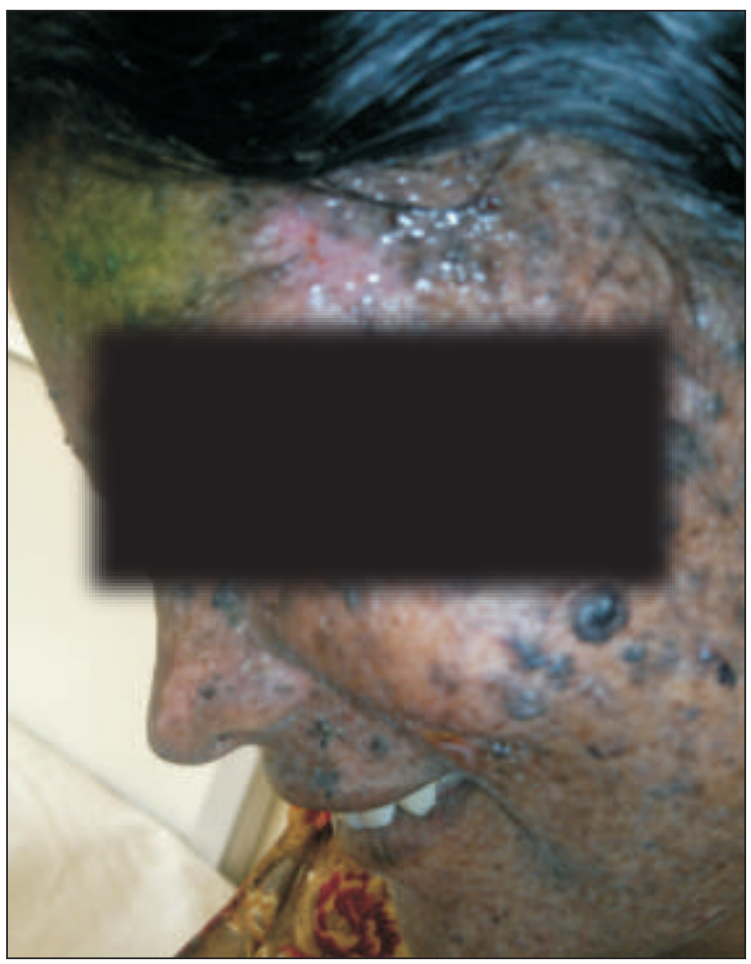

Figure 4. : Post excision and primary closure 